\section{Re: Effect of Nigella sativa against cisplatin induced nephrotoxicity in rats}

Dear Editor,

An interesting article was published in the Italian Journal of Food Safety entitled Effect of Nigella sativa against cisplatin induced nephrotoxicity in rats (Alsuhaibani, 2018). The authors used male SpragueDawley rats and concluded that Nigella sativa (NS) contain bioactive agents which protect the kidney against cisplatin induced nephrotoxicity (CIN). Almost similar research was conducted by Hosseinian et al. (2018) in male Wistar Albino rats, and they also found that NS has antioxidant protective effect in the kidney against CIN. Other investigators also reported the protective role of NS against CIN (Busari et al., 2018; Farooqui et al., 2017; Hadjzadeh et al., 2012), but one important point is necessary to mention here. The antioxidant effect of NS maybe gender related as it was found that losartan as antioxidant may protect the kidney against CIN in male but not in female rats (Haghighi et al., 2012). Naseem et al. (2015) reported that the ameliorative effect of riboflavin against $\mathrm{CIN}$ is gender related. The gamma-aminobutyric acid as supplement against CIN exacerbate renal damage in female (Peysepar et al., 2016), and pomegranate flower extract as antioxidant did not protect the kidney against CIN in female rats (Jilanchi et al., 2013). Vitamin E and l-arginine also have different effects on CIN between two genders (Jilanchi et al., 2014; Eshraghi-Jazi et al., 2011). Therefore, the protective role of NS against CIN may be gender related, and the interesting positive findings by Alsuhaibani (2018) may be failed in female. Furture studies may needed to finalyzied the protective role of NS on CIN

Mehdi Nematbakhsh, Water and Electrolytes Research Center/Department of Physiology, Isfahan University of Medical Sciences, Isfahan, Iran nematbakhsh@med.mui.ac.ir

\section{References}

Alsuhaibani AMA, 2018. Effect of Nigella sativa against cisplatin induced nephrotoxicity in rats. Ital J Food Safety 7:1059.

Busari AA, Adejare AA, Shodipe AF, Oduniyi OA, Ismail-Badmus KB, Oreagba IA, 2018. Protective but NonSynergistic Effects of Nigella Sativa and Vitamin E against CisplatinInduced Renal Toxicity and Oxidative Stress in Wistar Rats. Drug Res (in press).

Eshraghi-Jazi F, Nematbakhsh M, Nasri H, Talebi A, Haghighi M, Pezeshki Z, 2011. The protective role of endogenous nitric oxide donor (L-arginine) in cisplatin-induced nephrotoxicity: Gender related differences in rat model. J Res Med Sci 16:1389-96.

Farooqui Z, Ahmed F, Rizwan S, Shahid F, Khan AA, Khan F, 2017. Protective effect of Nigella sativa oil on cisplatin induced nephrotoxicity and oxidative damage in rat kidney. Biom Pharmacother 85:7-15.

Hadjzadeh MA, Keshavarzi Z, Tabatabaee
Yazdi SA, Ghasem Shirazi M, Rajaei Z, Khajavi Rad A, 2012. Effect of alcoholic extract of Nigella sativa on cisplatin-induced toxicity in rat. Iran J Kidney Dis 6:99-104.

Haghighi M, Nematbakhsh M, Talebi A, Nasri H, Ashrafi F, Roshanaei K, 2012. The role of angiotensin II receptor 1 (AT1) blockade in cisplatin-induced nephrotoxicity in rats: gender-related differences. Ren Fail 34:1046-51.

Hosseinian S, Hadjzadeh MA, Roshan NM, Khazaei M, Shahraki S, Mohebbati R, 2018. Renoprotective effect of Nigella sativa against cisplatin-induced nephrotoxicity and oxidative stress in rat. Saudi J Kidney Dis Transplant 29:1929.

Jilanchi S, Nematbakhsh M, Bahadorani M, Talebi A, Eshraghi-Jazi F, Mansouri A, 2013. Vitamin e is a nephroprotectant agent in male but not in female in a model of Cisplatin-induced nephrotoxicity. ISRN Nephrol 2013:280395.

Jilanchi S, Nematbakhsh M, Mazaheri S, Talebi A, Zolfaghari B, Pezeshki Z, 2014. Pomegranate Flower Extract does not Prevent Cisplatin-Induced Nephrotoxicity in Female Rats. Int J Prev Med 5:1621-5.

Naseem I, Hassan I, Alhazza IM, Chibber S, 2015. Protective effect of riboflavin on cisplatin induced toxicities: a genderdependent study. Journal of trace elements in medicine and biology 29:30314.

Peysepar E, Soltani N, Nematbakhsh M, Eshraghi-Jazi F, Talebi A, 2016. Gamma-aminobutyric acid aggravates nephrotoxicity induced by cisplatin in female rats. J Renal Injury Prev 5:18892. 